\title{
Psychiatry in Jamaica
}

\author{
Claire Hilton
}

\begin{abstract}
Jamaica has ons large mental hoeplital. Recent developments in community core have reduced the number of in-patients. Mout patients with serious poychiatic tiness ilve in the community, supported by their familles and nurses with some poychiatic training. subetence cbuse is a major problem, and the sulcids rate is reported to have tisen recently.
\end{abstract}

For 200 years, white slave masters forced black African slaves to labour on the plantations in Jamaica. Slavery was officially abolished in 1838 , although slave masters became the new employers, and harsh work regimes and low salaries tended to continue a pattern of established cruelty. The period of slavery has influenced life in Jamaica into the twentieth century, including the care of the mentally lll. Hickling (1993) suggested that mental illness was tolerated by the African community, but was intolerable to the British, and that mentally ill slaves were frequently incarcerated in cellars by their owners.

In 1962, Jamaica became independent. It has a population of 2.5 million and is still a developing country. A national survey indicated that only $39 \%$ of dwellings had piped water indoors, 52\% had a flush tollet and $66 \%$ had electricity (STATIN, 1990). Among the wealthy minority, a family may spend 2500 Jamaican dollars ( $\$ 50)$ a week in the supermarket. By contrast, the majority of the population are lower class, and an income of 600 Jamaican dollars a week (£10) is not uncommon.

During a five-month visit to Jamaica in 1994 collecting data on psychiatric complications of sickle cell disease, I made contact with many of the psychiatrists and psychiatric services in the island.

\section{Bellevue Hospital}

The Bellevue Hospital is the only large mental Hospital in Jamaica. It was opened in 1862 and still houses 1300 patients in huge wards, dilapidated and dingy, linked by a network of open-sided corridors. Here, goats graze, patients sit and wander, and washing is hung out to dry. Almost $10 \%$ of the bulldings are deemed unfit for occupancy (STATIN, 1992). It is not uncommon to see an out-patient sitting on the grass waiting to be seen, hand-cuffed or with hands and feet bound with rope. All in-patients pass through the admissions room, where doctor, nurse and administrator sit side by side, each interviewing a different patient or his relatives. The admissions ward is kept locked, but marijuana ("ganja") can be smuggled in through the ever open but barred windows. Against the odds, with limited funding and with fewer than half a dozen junior doctors. the senior medical officer coordinates the provision of psychiatric care. Ward staff are enthuslastic and organise activities, and an occupational therapy and rehabilitation unit function within the grounds. However, care is mainly custodial since the closure of a rehabilitation programme by the government which came into power in 1980 (Hickling, 1993).

There are no acute psychiatric in-patient units outside Kingston and psychotic patients are frequently admitted to general medical wards without specialist psychiatric care (Hickling, 1991). The only psychiatric rehabilitation unit outside Kingston has extremely limited resources. For example, it is unable to rehabilitate patients in the use of money since there are neither social security payments nor any token financial incentives available.

Admissions to Bellevue Hospital fell considerably from 136 per 100000 population in 1971 to 69 per 100000 in 1988 . This has been attributed to the development of community mental health services (Hickling. 1991). Most people with serious mental illnesses live in the community with very caring families. Mothers, daughters and sisters of patients frequently attend clinics, offer support and supervise medication. Jamaicans are strongly kdn-oriented. Most women 'father' in addition to mothering their children, because economic and traditional constraints keep "babyfathers' from fulfilling the provider role, and participating in the upbringing of their children (Sobo, 1993). Traditional constraints on the father date back to the era of slavery when the residential unit on the plantations was mother and children only, with responsibility for their maintenance resting on the slave owner. The father's place in the family was never secure, he had no sanctions over it and at any time could be removed from it. Families headed by a single mother, with father absent, remain a common pattern in Jamaica today.

If a patient becomes estranged from his family, he may find himself on the streets, and from there 
in a surgical ward following a road traffic accident or gunshot wound. Eventually he may be discharged to a back ward at Bellevue. For the destltute there is little support. Food stamps are issued under the Poor Law, but periodically new referrals are refused for months on end.

\section{Mental health officers - the backbone of community care}

Most adult users of the psychiatric services have psychotic illnesses. A recent island-wide survey using the Present State Examination, a standardised psychiatric research interview, showed a low incidence of schizophrenia, far lower than that found in Jamaican families in Britain (Hickling \& Rogers-Johnson, 1994). Many patients with schizophrenia recetve psychiatric care and depot neuroleptics at 'Modecate Clinics' run by the mental health officers-general nurses with experience in psychiatry who have completed a nine-month course in psychiatric nursing. They deal with the routine care of patients with psychotic illness, and are the mainstay of mental health care in Jamaica. Some work almost independently of psychiatrists, and in rural areas may initiate treatment, including medication. They are involved with many aspects of psychiatry, from child mental illness to HIV counselling. They have a huge responsibility, often with inadequate financial resources, and insufficient in-service training to keep up to date with current psychiatric practice. Psychiatrists are few and far between, with less than ten consultants for the entire population.

\section{Substance abuse}

Substance abuse, especially alcohol, is a major health problem in Jamaica, and in the rest of the Caribbean (Hickling, 1993). Marijuana is cheap and widely used. Cocaine is used far less, but is a recognised problem. Narcotic use is rare. The University Hospital has an eight-bed alcohol and drug detoxification unit. Staff are enthusiastic and well trained by experts from the USA. They work alongside Alcoholics Anonymous, but badly need more dry hostels and half-way houses. Sadly, the unit is too small, and many patients cannot afford the charges of other, private clinics.

\section{Suicide}

Headlines in The Gleaner, Jamaica's main national daily newspaper, recently reported a fourfold increase in rates of suicide (Williams, 1995). These had been estimated to be very low, 1.4 per 100000 population, in a carefully devised study of all Jamaicans who had died suddenly in 1975-76 (Burke, 1985). The study also identified particularly low rates in women $(0.6$ per 100 000), and suggested that the stable environment of a traditional society, and in particular a clearly defined female role, act as a defence against suicide. It is not possible to pinpoint the reasons for the recent increase, although there are major changes taking place in Jamaican society, particularly for women. For example, the number of children born per woman has fallen from 6 to 3 in the last 20 years, two-thirds of graduates from the Untversity of the West Indies are women, and women are becoming high achievers in medicine, business, law and politics. Among extended families, it is not a new phenomenon for young children to be sent to grandmothers or aunts when the mother migrates from the country to Kingston, or abroad, to seek education or employment. However, it was observed in a child psychiatry clinic that children separated from their parents or parent figures tended to have more mood swings, showed antisocial behaviour and had lower IQs than those without a history of separation (Wray \& McLarren, 1976).

\section{The Mental Hospital Act 1873}

Current mental health legislation dates from 1873, with a few amendments made in the last couple of decades. Until 1974, a mentally ill person could be arrested by the police on a charge of lunacy and sent to Bellevue. At the time of my visit, a new Bill had been drafted, but it urgently needed revising. For example, it did not specify a maximum duration of detention. and it stated that a voluntary patient may only be discharged on receipt of a written request and "shall not be kept in a psychiatric facility for more than seven days" from the date the request is received. However, plans for community supervision and a system of review for involuntary patients were included.

\section{Attitudes to mental illness, and the future}

I asked several psychiatrists why many acres of unused land at Bellevue Hospital, in the heart of Kingston, are not sold and the proceeds used to fund a community psychiatric programme. They frequently referred to the intense stigma attached to mental illness in Jamaica, and its likely adverse effects on community care. The Statistical Year Book of Jamaica (STATIN, 1992) states explicitly that "Negattve public perceptions of the mentally ill and their potential for productive lives limit interest and support for psychiatric services and a truly comprehenstve, integrated psychiatric delivery system". However, stigma appeared far less evident than I had been led to 
suppose. For example, there was clearly a demand for treatment of minor psychiatric illnesses, as demonstrated by the success of the Bethel Baptist Medical and Counselling Centre in Kingston which has a flourishing counselling service. Hickling (1991) suggested that decentralisation of psychiatric care to the community has already led to a reduction in the stigma attached to mental illness, although it was unclear how this was measured. It is unknown how much traditional beliefs and healing by obeah, bush healers and Church healers have influenced popular attitudes to psychiatry. This aspect of mental health was not explored during my visit to the island. Although no major studies of health beliefs and folk aetiology have been carried out in Jamaica, it appears that bizarre behaviour is considered the main component of mental illness, and withdrawal and depression are excluded.

\section{Financial constraints}

Finances for health care are limited. One Jamaican psychiatrist suggested that in a situation of budgetary constraints there is "the sometimes unconscious notion that money spent on mental health programmes could have been better utilised" (La Grenade, 1991). Michael Beaubrun, Professor of Psychiatry in Jamaica, stated in 1984. "There is no dearth of mental health plans in the Commonwealth Caribbean. Indeed the problem is rather a lack of implementation and a tendency to reinvent the wheel" (La Grenade, 1991). Individual psychiatrists practise with enthusiasm, in spite of the lack of facilities. Even at the University Hospital, psychiatric clinics are often cramped with only a curtain separating the patient being interviewed from those in the waiting room. At a health centre outside Kingston, the noise from the waiting area through the thin wooden partition and the hum of the old electric fan made it difficult to even hear the patients talk. In spite of the drawbacks, the University Hospital trains psychiatrists for all parts of the Caribbean. The four year postgraduate training programme includes clinical experience in substance abuse and child psychiatry, and a year of research.

\section{Jamaican patients in Britain}

This article has concentrated on the public psychiatric services available to the majority of the Jamaican population. Private psychiatric care is also available for those who can afford it. Jamaican patients in Britain may wish to return to their country of origin either for a holiday or permanently. A knowledge of psychiatric care available may be important in making these decisions.

Ethnic minority groups in Britain may also have cultural beliefs both about mental illness and psychiatric services in their countries of origin. These may influence their perceptions of psychiatrists and psychiatric services in Britain and may be among the factors contributing to the sometimes volatile encounters between patients and mental health workers. An understanding of cultural issues, some of which have been outlined here, may be of benefit in managing patients from the Jamaican community in Britain.

\section{Acknowledgements}

The visit to Jamaica was supported by the Lilly Travelling Fellowship of the Royal College of Psychiatrists (1993), and a Neurosciences Research Fellowship from the Wellcome Trust. I am also grateful to Dr Madeline Osborn for her support.

\section{References}

BURKE, A. W. (1985) Suictde in Jamalca. West Indian Medical Joumal, 34, 48-53.

Hickung, F. W. (1991) Psychlatric hospital admission rates in Jamaica: 1971 and 1988. Britlsh Journal of Psychiatry, 169, 817-821.

- (1993) Psychlatry in Jamaica - growth and development. International Revlew of Psychiatry. 5, 193-203.

- \& ROGERSJOHNSON, P. (1994) The incidence of first contact schizophrenia in Jamaica (Proceedings of the 39th Sclentific Meeting. Commonwealth Caribbean Medical Research Councll, Jamaica) (Abstract). West Indian Medical Joumal, 43 (Suppl. 1), 12.

LA GRENADE, J. (1990) Progress in mental health in the Commonwealth Caribbean - Strategles and plans for future action. In Proceedings of the Inaugural Meeting and Conference of the Carbbean Public Health Assoctation. Jamaica: Carlbbean Public Health Association.

SOBO. E. J. (1993) One Blood: the Jamalcan Body. New York: State Untversity of New York Press.

STATIN (1990) The Jamaica Survey of Living Conditions. Kingston: Statistical Institute of Jamaica.

- (1992) Statistical Year Book of Jamaica. Kingston: The Statistical Institute of Jamaica.

Wiunas, G. (1994) Suicide rate soars. The Sunday Gleaner. April 3rd.

WRAY, S. R. \& MCLARREN, E. (1976) Parent-child separation as a determinant of psychopathology in children: a Jamaican study. West Indian Medical Journal, 25. 251-257.

Claire Hilton, Senior Registrar, Department of Psychiatry, Withington Hospital, Nell Lane, Manchester M20 8LR 